\title{
Development of New Candidate Gene and EST-Based Molecular Markers for Gossypium Species
}

\author{
Ramesh Buyyarapu, ${ }^{1}$ Ramesh V. Kantety, ${ }^{1}$ John Z. Yu, ${ }^{2}$ \\ Sukumar Saha, ${ }^{3}$ and Govind C. Sharma ${ }^{1}$ \\ ${ }^{1}$ Center for Molecular Biology, Department of Natural Resources and Environmental Sciences, Alabama A\&M University, \\ 134 ARC Building, P.O. Box 1927, Normal, AL 35762, USA \\ ${ }^{2}$ Southern Plains Agricultural Research Center, USDA-ARS, 2881 F\&B Road, College Station, TX 77845, USA \\ ${ }^{3}$ Genetics and Precision Agriculture Research Unit, USDA-ARS, P.O. Box 5367, MS 39762, USA \\ Correspondence should be addressed to Ramesh V. Kantety, ramesh.kantety@aamu.edu
}

Received 31 August 2011; Revised 26 October 2011; Accepted 9 November 2011

Academic Editor: Haibao Tang

Copyright ( $\odot 2011$ Ramesh Buyyarapu et al. This is an open access article distributed under the Creative Commons Attribution License, which permits unrestricted use, distribution, and reproduction in any medium, provided the original work is properly cited.

\begin{abstract}
New source of molecular markers accelerate the efforts in improving cotton fiber traits and aid in developing high-density integrated genetic maps. We developed new markers based on candidate genes and G. arboreum EST sequences that were used for polymorphism detection followed by genetic and physical mapping. Nineteen gene-based markers were surveyed for polymorphism detection in 26 Gossypium species. Cluster analysis generated a phylogenetic tree with four major sub-clusters for 23 species while three species branched out individually. CAP method enhanced the rate of polymorphism of candidate gene-based markers between G. hirsutum and G. barbadense. Two hundred A-genome based SSR markers were designed after datamining of G. arboreum EST sequences (Mississippi Gossypium arboreum EST-SSR: MGAES). Over 70\% of MGAES markers successfully produced amplicons while 65 of them demonstrated polymorphism between the parents of G. hirsutum and G. barbadense RIL population and formed 14 linkage groups. Chromosomal localization of both candidate gene-based and MGAES markers was assisted by euploid and hypoaneuploid CS-B analysis. Gene-based and MGAES markers were highly informative as they were designed from candidate genes and fiber transcriptome with a potential to be integrated into the existing cotton genetic and physical maps.
\end{abstract}

\section{Introduction}

Molecular markers provide valuable information in assessing the genetic variability, generating linkage maps, enabling better understanding of the genome organization, and deciphering quantitative trait loci (QTLs). Initial effort to map the cotton genome using an $\mathrm{F}_{2}$ population utilized 705 restriction fragment length polymorphism (RFLP) probes that were polymorphic between G. hirsutum and G. barbadense and generated 41 linkage groups spanning $4675 \mathrm{cM}$ [1]. Genetic variation at molecular level in cotton has been characterized using isozyme/allozyme markers [2], RFLPs [1, $3,4]$, AFLPs $[5,6]$, and microsatellites $[7,8]$ in G. hirsutum and its related species. A comprehensive comparative genetic map with 2584 loci at $\sim 1.72 \mathrm{cM}$ intervals for tetraploid
$\left(\mathrm{A}_{\mathrm{t}} \mathrm{D}_{\mathrm{t}}\right)$ cotton and with 662 loci at $\sim 1.96 \mathrm{cM}$ intervals for diploid (D) genome was constructed using RFLPs, genomic SSRs, and sequence tagged sites (STS) as probes [9].

Advances in technology have facilitated sequencing of complete transcriptomes and genomes that are accessible through public domain databases. Increasing number of expressed sequence tags (ESTs) for cotton facilitated the identification of simple sequence repeat (SSR) regions from the ESTs through data mining techniques. EST-SSR markers reveal putative functional genes and aid in map-based cloning of important genes $[10,11]$. In cotton, several EST-SSRs have been recently mapped [12-15]. Cotton fiber genes were mapped with EST-derived SSR loci using recombinant inbred line (RIL) population derived from an interspecific cross between $G$. hirsutum $\times G$. barbadense 
[16]. Other alternative mapping approaches such as wholegenome radiation hybrid (WGRH) mapping and fluorescent in situ hybridization (FISH) mapping have been utilized to generate an integrated cotton genome map [17].

Assignment of linkage groups or markers to chromosomes is made by use of aneuploid chromosome substitution ( $F_{1}$ Stocks) lines of G. barbadense in G. hirsutum, euploid chromosome substitution lines of G. barbadense in G. hirsutum, and aneuploid chromosome substitution ( $\mathrm{F}_{1}$ Stocks) lines of G. tomentosum in G. hirsutum [18]. Euploid chromosome substitution stocks were developed by inbreeding the hemizygous monosomic and monotelodisomic substitution stocks through backcrossing up to $\mathrm{BC}_{5}$ generation [19]. Using these available substitution lines, various molecular markers, linkage groups, and QTLs for agronomic and fiber quality traits were physically mapped to different cotton chromosomes $[1,9,20]$.

Current integrated genetic maps in cotton utilized mainly RFLP, AFLP, genomic SSR, STS, and EST-SSRs. However, increasing the marker density with functionally expressed genes would make the linkage maps more valuable for crop improvement programs. New sources of molecular markers such as cleaved amplified fragment polymorphism (CAP), EST-SSR, and single nucleotide polymorphism (SNP) markers expand the current but limited repertoire of existing molecular markers. In this study, our objective was to understand the genetic diversity and phylogeny of the cultivated tetraploid, and wild diploid cotton species including the Cotton Marker Database (CMD) panel through the evaluation of candidate genes, CAP and EST-SSR marker technologies, and to use these markers in the construction of integrated genetic and physical maps in cotton.

Sequence information of candidate genes available in related species for functional genes helps in designing primers to amplify and differentiate between the species. CAP markers are extensively used in human and animal sciences while they were not exploited well in plant sciences for mapping [21]. CAP is an effective technology that uses PCR and restriction digestion to elucidate the polymorphism at nucleotide level without the knowledge of the sequence information of a marker. Using the abundant sequence information available for G. arboreum (diploid) fiber ESTs in GenBank, we designed over 700 nonredundant primer pairs based on the identification of the SSR regions, and tested 200 primer pairs using the two major cultivated tetraploid species G. hirsutum (TM-1) and G. barbadense (3-79), the parents for RIL population used in this study. Polymorphic markers were used for genetic mapping using an RIL population, and were further physically localized through the use of monosomic, monotelosomic aneuploid, and euploid chromosome substitution lines of G. barbadense in G. hirsutum genetic background.

\section{Materials and Methods}

2.1. Genetic Materials. Leaf samples were collected from the Cotton Germplasm Research Unit greenhouses at USDAARS, College Station, TX, for (1) Cotton Marker Database (CMD) panel (12 genotypes of six Gossypium species) [22]
TABLE 1: Cotton genotypes used for polymorphism detection and phylogenetic tree.

\begin{tabular}{|c|c|c|}
\hline No. & Species/genotype & Genome \\
\hline 1 & G. hirsutum/TM-1 & AD1 (CMD1) \\
\hline 2 & G. barbadense/3-79 & AD2 (CMD2) \\
\hline 3 & Acala maxxa & AD1 (CMD3) \\
\hline 4 & DPL $458 B R$ & AD1 (CMD4) \\
\hline 5 & Paymaster 1218BR & AD1 (CMD5) \\
\hline 6 & Fibermax 832 & AD1 (CMD6) \\
\hline 7 & Stoneville $4892 B R$ & AD1 (CMD7) \\
\hline 8 & PIMA S-6 & AD2 (CMD8) \\
\hline 9 & G. arboreum & A2 (CMD9) \\
\hline 10 & G. raimondii & D5-3 (CMD10) \\
\hline 11 & G. tomentosum & AD3 (CMD11) \\
\hline 12 & G. mustelinum & AD4 (CMD12) \\
\hline 13 & G. darwinii & AD5 \\
\hline 14 & G. triphyllum & $\mathrm{B} 2$ \\
\hline 15 & G. sturtianum & $\mathrm{C} 1$ \\
\hline 16 & G. areysianum & E3 \\
\hline 17 & G. australe & C3 \\
\hline 18 & G. costulatum & C5 \\
\hline 19 & G. pulchellum & $\mathrm{C} 8$ \\
\hline 20 & G. thurberi & D1 \\
\hline 21 & G. armourianum & D2-1 \\
\hline 22 & G. harknessii & D2-2 \\
\hline 23 & G. klotzschianum & D3K \\
\hline 24 & G. aridium & D4 \\
\hline 25 & G. gossypioides & D6 \\
\hline 26 & G. lobatum & D7 \\
\hline 27 & G. trilobum & D8 \\
\hline 28 & G. turneri & D10 \\
\hline 29 & G. schwendimanii & D11 \\
\hline 30 & G. stocksii & E1 \\
\hline 31 & G. somalense & E2 \\
\hline 32 & G. bickii & G1 \\
\hline
\end{tabular}

and (2) other geographically diverse tetraploid species and wild diploid accessions (Table 1). Leaf samples were also collected from USDA-ARS Mississippi State, MS, for aneuploid chromosome substitution lines $\left(\mathrm{BC}_{0} \mathrm{~F}_{1}\right)$ of $\mathrm{G}$. barbadense in G. hirsutum and seventeen euploid chromosome substitution lines of G. barbadense in G. hirsutum. Genomic DNA of 186 individual RILs derived from a cross between TM-1 x 3-79 were provided by USDA-ARS, Southern Plains Agricultural Research Center, Crop Germplasm Research Unit, College Station, TX.

2.2. DNA Extraction. Young leaf tissues were lyophilized and the DNA was extracted using the Yu lab method at USDA-ARS, College Station, TX [23]. DNA quality was evaluated using $0.7 \%$ agarose gel electrophoresis at $40 \mathrm{~V}$ for 3 hours. Genomic DNA was also quantified using TKO 100 fluorometer and further diluted to a working concentration of $50 \mathrm{ng} / \mu \mathrm{L}$ for use in polymerase chain reaction (PCR). 
2.3. Gene-Based Markers. G. arboreum EST sequences in GenBank were compared with non-redundant (nr) protein database to derive the putative gene function using BLASTX program. ESTs that had significant homology with functional genes in Arabidopsis, Oryza, and others were selected for polymorphism screening. Forty-seven primer pairs were synthesized (Sigma Genosys, The Woodlands, TX) based on these candidate genes that have functional significance in cotton (See Supplementary File-1 in supplementary material available on line at doi:10.1155/2011/894598). Primers were evaluated for amplification using PCR at two annealing conditions $\left(\mathrm{T}_{m}=50^{\circ} \mathrm{C}\right.$ and $60-55$ touchdown). Amplified products were surveyed for polymorphism using $6 \%$ polyacrylamide gel electrophoresis (PAGE) and scored in binary fashion for each fragment size. The data was used to calculate the Polymorphism Information Content (PIC) value. Cluster analysis was conducted with nearest neighborhood joining method in classifying the binary data derived to generate phylogenetic tree to assess the evolutionary relationships [24] among the five tetraploid and 21 diploid species. PCR products of the monomorphic markers between G. hirsutum and G. barbadense were subjected to digestion using RsaI, MspI, HhaI, and HaeIII restriction endonucleases and surveyed for polymorphism using PAGE for detection of CAP markers. Fragment-based and CAP-based markers were subsequently tested for chromosomal localization in aneuploid and euploid chromosome substitution lines.

2.4. EST-SSR-Based Markers. G. arboreum ESTs $(38,893)$ were collected from GenBank and were searched for the presence of SSR sequences, followed by masking. The masked ESTs were clustered using StackPack v2.1 (Electric Genetics, Reston, VA) software to reduce the redundancy. The nonredundant (NR) sequences that contain an SSR motif were selected for further analysis as described by Kantety et al. [25]. A subset of NR-ESTs mainly expressed in fibers (725) were identified with having a repeat length 18 or more. Among this subset SSR containing NR-ESTs, we designed 200 primer-pairs for further analysis. They were designated as Mississippi Gossypium arboreum EST-SSRs (MGAES). The design of the primers was based on the sequence information flanking the SSR region with an estimated product size of 200-300 base pairs using Primer3 software [26] and were synthesized at Sigma-Genosys (Sigma-Aldrich, Saint Louis, $\mathrm{MO})$. The primer sequences, EST sources, and their putative function were summarized in Supplementary File-2. The MGAES primers were verified against all the SSR marker primer sequences available at Cotton Microsatellite Database (CMD, http://www.cottonmarker.org/) for redundancy and sequence homology using BLAST search. These MGAES and gene-based primer sequences will be submitted to CMD for cotton research community use. MGAES primers were first amplified on the RIL parents: G. hirsutum and G. barbadense, at annealing conditions of $50^{\circ} \mathrm{C}$ and $55^{\circ} \mathrm{C}$; and surveyed for fragment length polymorphism using 6\% PAGE. Polymorphic markers were then identified to genotype the RIL population for construction of genetic linkage groups. The amplified markers were also used for physical mapping onto chromosomes and chromosome arms.
2.5. Data Analysis. Polymorphic data was scored as binary values ( 1 as presence of fragment, 0 as absence) and used for the calculation of PIC value [27]. Binary data was also used to generate a phylogram using cluster analysis with SAS v9.1 (SAS Inc, Cary, NC). Similarly, binary data from RIL population for polymorphic fragments were used to create linkage groups using MapManager QTX software [28]. Recombination frequencies were converted into linkage distances using Haldane function [29]. The maximum linkage distance below $50 \mathrm{cM}$ between any two markers and an LOD (logarithm of odds) score of 4 and above were considered optimal to qualify as a linkage group.

\section{Results and Discussion}

3.1. Candidate Gene-Based Markers. The thrust of this effort was to expand the very limited base of markers that are utilized in characterizing genetic variability in Gossypium. Comparative genetic approaches have been proved successful for characterizing genomes and mapping important traits based on the sequence information in related plant species [30]. Candidate genes in G. arboreum EST sequences were identified by comparison with distant species using BLASTX to reveal the gene function information and such ESTs were used to design primers. Nineteen candidate gene markers (40\%) were successfully amplified out of 47 gene-based markers screened across the 32 genotypes from 26 diverse Gossypium species tested in this study. PAGE fragment analysis for amplified products identified 13 markers that were polymorphic among these cotton species $(68 \%)$. Binary fragment data for these markers were used to calculate PIC value for each marker that ranged from 0.794 to 0.998 (Table 2).

Though these gene-based markers were highly polymorphic across multiple cotton species, the fragment polymorphism rates detected using direct amplicons were very low for the two cultivated tetraploids versus G. hirsutum and G. barbadense. Only one polymorphic marker was identified between G. hirsutum TM-1 (CMD-1) and G. barbadense PIMA 3-79 (CMD-2). This limitation led us to explore additional avenues by restriction digestion of the large PCR fragments to survey for polymorphism at a higher resolution. CAP markers have been used in marker-assisted selection process and mapping genetic loci of interest [21,31]. Large amplicon sizes for many gene-based markers provided an opportunity to employ CAP technique to detect nucleotide level polymorphism for TM-1 and PIMA 3-79. To enable higher restriction site choices in these amplicons, we used RsaI, MspI, HhaI, and HaeIII enzymes that detect four base restriction site recognition motifs. CAP technique identified eleven polymorphic markers (58\%) of the 19 tested on TM-1 and PIMA 3-79 suggesting the potential for CAP technology as a useful resource for identifying genetic variation. One fragment-based and five CAP-based markers were localized to cotton chromosome or chromosome-arm using the euploid CS-B lines. Our results suggest that CAP-based marker technology is a robust approach for detection of variation in closely related species and provides an alternative to cost-intensive SNP-based approaches. 
TABLE 2: Polymorphism information content and chromosomal localization of gene-based markers by CAP technique.

\begin{tabular}{|c|c|c|c|c|}
\hline Marker & Putative gene & PIC value & Restriction enzyme & Chromosome \\
\hline BG2926 & Actin gene & 0.949 & - & - \\
\hline BG7042 & S-adenosyl-L-methionine decarboxylase proenzyme & 0.997 & - & - \\
\hline BG7067 & Low MW heat shock protein gene (Gmhsp17.6-L) & 0.988 & - & - \\
\hline BG7092 & Glyceraldehyde-3-phosphate dehydrogenase & 0.981 & - & - \\
\hline BG7164 & Mitogen-activated protein kinase (MAPK) & 0.917 & - & - \\
\hline BG7197 & Auxin induced basic helix-loop-helix transcription factor & 0.934 & - & - \\
\hline BG7211 & DNA-binding protein (WRKY 1) & 0.967 & RsaI & 11 short arm \\
\hline BG7213 & Zinc finger protein (TIM9) & 0.908 & - & - \\
\hline BG7215 & Acyl CoA independent ceramide & 0.912 & RsaI & 6 \\
\hline BG7226 & Potassium transporter HAK3p & 0.967 & - & - \\
\hline BG7238 & Photolyase/blue light photoreceptor phr2 & 0.849 & - & - \\
\hline BG7314 & Copalyl diphosphate synthase 1 & 0.954 & HaeIII & 14 short arm, 25 \\
\hline BG7356 & Omega-3 fatty acid desaturase (FAD3) & 0.902 & - & - \\
\hline BG7405 & Transcription factor (Hap5a) & 0.967 & HhaI & $10,16,22$ Short arm \\
\hline BG7411 & Ubiquitin extension protein & 0.849 & - & - \\
\hline BG7428 & Cinnamic acid 4-hydroxylase & 0.794 & - & - \\
\hline BG7443 & Small heat stress protein & 0.952 & MspI & 16 \\
\hline BG7446 & G-protein beta subunit & 0.84 & - & - \\
\hline BG7485 & Flavonoid 3'-hydroxylase & 0.998 & HhaI & 16 \\
\hline
\end{tabular}

Euploid CS-B lines were annotated on the basis of the chromosome pair substituted for the complete chromosomes or chromosome arms of G. hirsutum monosomic or monotelodisomics [19, 32]. If a polymorphic marker between G. hirsutum and G. barbadense showed similar fragment patterns to that of $G$. barbadense in a euploid CS-B line, then that marker was concluded to be localized to particular substituted chromosome or arm. In this manner, both dominant and recessive alleles were physically mapped using euploid CS-B lines. One amplicon length polymorphism and five CAP-based markers were localized to seven chromosomes or arms using the euploid CS-B lines (Table 2). As these markers were based on homologous gene sequences, there is a possibility of having multiple copies in the tetraploid cotton genomes. Therefore this study adds a new set of gene-based markers with their specific chromosomal location and help in assessing the evolutionary relationships among the 26 Gossypium species.

3.2. Phylogenetic Analysis. Gossypium genus includes five tetraploid species from $\mathrm{AD}_{1}-\mathrm{AD}_{5}$ genomes and approximately forty-five diploid species from genome groups $A-G$ and $\mathrm{K}[33]$. Of these all five tetraploid species and twenty-one diploid species belonging to $\mathrm{A}(1), \mathrm{B}(1), \mathrm{C}(4), \mathrm{D}(11), \mathrm{E}(3)$, and $G(1)$ genomes were included in this study. Relationships among these cotton genome groups were studied earlier using polymorphisms exhibited in chloroplast genome [34], ribosomal genes [35], and $A d h$ genes [36]. These studies showed close relationships among the species belonging to the same geographical origin [37] besides explaining the origin of New World tetraploids from the Old World diploids [38].

In this study, a total of 76 fragments from nineteen candidate gene-based markers were observed across the diverse panel of 32 cotton genotypes. Binary data derived from the fragment analysis was used to generate a phylogenetic tree providing the evolutionary relationships among the 26 cotton species by cluster analysis using maximum likelihood method (Figure 1). Cluster analysis resulted in a dendrogram comprising four major clusters grouping 23 species except that G. bickii (G1), G. pulchellum (C3), and G. australe (C8) branched out individually. As the dendrogram was derived based on the maximum likelihood method, it provides the evolutionary relationships based on combined genetic lineages of the candidate genes used in this study. Many genotypes from tetraploid species formed into two clades while the diploid species form the remaining. Species belonging to the same genome are grouped together to form subclusters in the dendrogram and was evident in grouping of tetraploids as wells as other diploid species. Though the number of genes used in this study is not an exhaustive data set, the evolutionary relationships among the 26 species were mostly congruent with earlier studies [37]. The dendrogram also supported the theory that $G$. darwinii $\left(\mathrm{AD}_{5}\right)$, another tetraploid species endemic to Galapagos Islands is closely related to $G$. barbadense $\left(\mathrm{AD}_{2}\right)[39,40]$.

3.3. G. arboretum EST-SSR Markers. Availability of abundant EST information in public databases and detection procedures to identify SSR regions in ESTs have established 


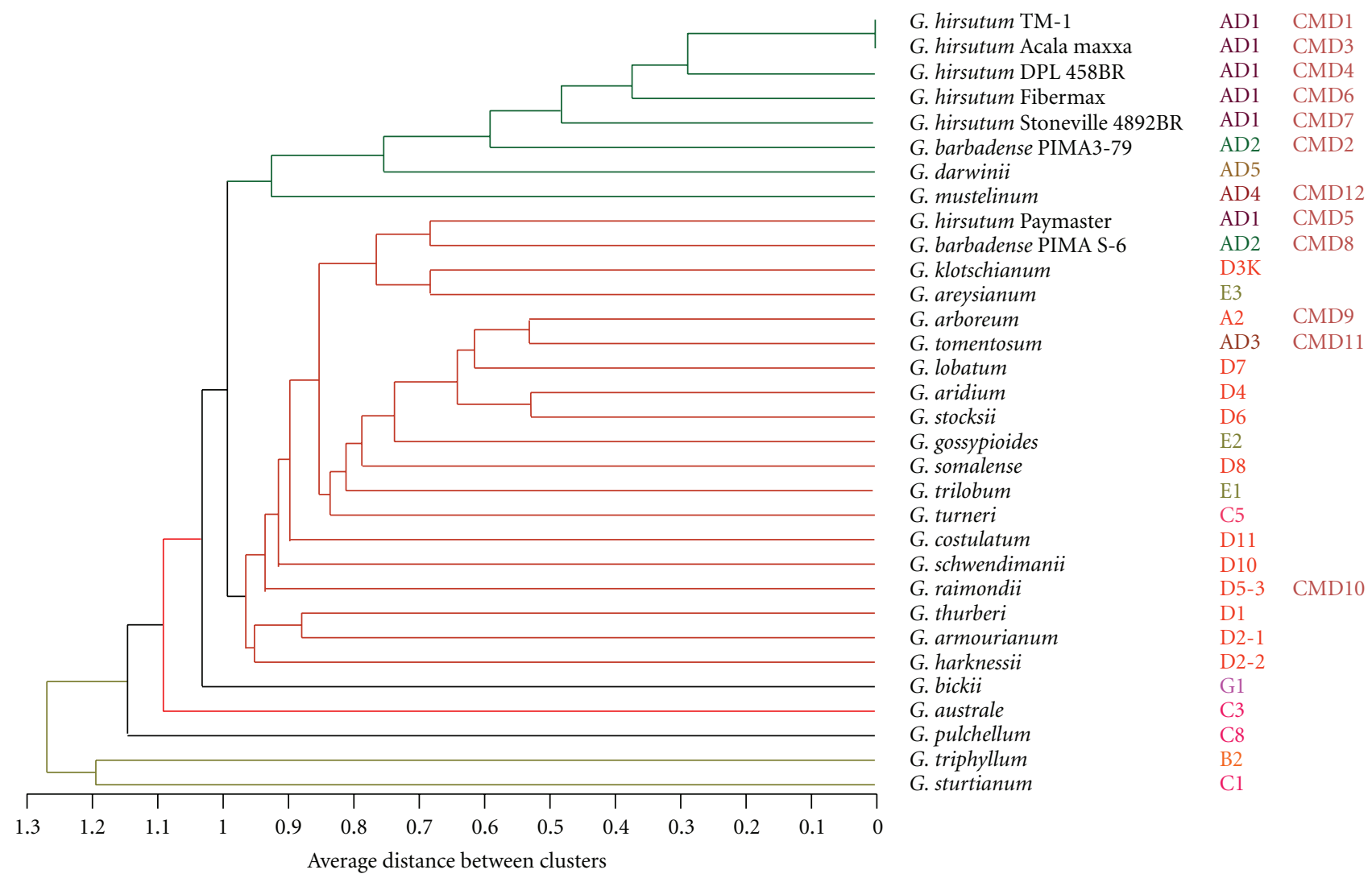

FIgUre 1: Phylogenetic relationships among the 32 Gossypium genotypes (Table 1) based on the fragment size polymorphism.

EST-SSRs as an informative resource for genetic mapping $[7,12,14,25,41]$. Despite the earlier efforts by Han et al. [15] and Part et al. [16] to characterize cotton genome using EST-SSRs, the molecular variation in the coding regions of many fiber expressed genes was not yet fully utilized to assist the marker-assisted selection of important fiber traits. Two hundred primer pairs were designed specifically from fiber related ESTs were used for polymorphism detection and mapping in this study. Except 27 individual primer sequences, the rest of the MGAES markers were new and nonrepetitive based on BLAST homology search from earlier studies of Han et al. [15] and Park et al. [41]. Though these EST-SSRs were derived from a diploid progenitor (genome $\left.A_{1-2}\right)$ of tetraploid species $\left(A_{t} D_{t}\right), 147$ markers (74\%) out of 200 primer pairs were successfully amplified in tetraploid cultivars G. hirsutum TM-1 and G. barbadense PIMA 3-79 suggesting considerable homology exists of the tetraploid cotton with the diploid ancestral species. Sixtyfive MGAES markers (44\%) were polymorphic between TM1 and PIMA 3-79 indicating the merit of these markers due to high rate of polymorphism compared to earlier studies [15]. Though these G. arboreum EST-SSR markers were highly polymorphic between the G. hirsutum and G. barbadense species, we observed very low polymorphism rate within each species. High polymorphic rate between the species could also be attributed to amplification of genotypes under stringent PCR conditions to avoid nonspecific amplification. High levels of polymorphism were detected using G. arboreum-based EST-SSRs suggested the potential of cross-species transferability of these markers among diploid and tetraploid species [42]. Many of these MGAES markers were derived from the fiber expressed ESTs thus making them more valuable in breeding programs and marker-assisted selection for fiber-associated traits. Polymorphism detected for each fragment in 186 RILs was scored initially in ternary fashion and then converted into binary fashion by treating the heterozygous alleles as missing values. MapManager program was used for constructing linkage groups. Fourteen linkage groups were generated spanning $\sim 399 \mathrm{cM}$ with minimum two markers for linkage group and with an LOD score threshold of 4 . These linkage groups and polymorphic markers can be incorporated into existing genetic maps to generate an integrated genetic map for cotton.

3.4. Chromosomal Localization of MGAES Markers. Physical mapping of the polymorphic markers was facilitated using aneuploid (Figure 2) and euploid chromosome substitution lines (Figure 3). Sixteen markers were localized to different chromosomes using euploid CS-B lines while 14 markers were localized using aneuploid CS-B lines. Missing a polymorphic locus in a specific aneuploid $\left(\mathrm{BC}_{0} \mathrm{~F}_{1}\right)$ accession determines the chromosomal localization of a dominant marker to that corresponding specific chromosome or chromosome arm. Results derived from both aneuploid and euploid CS-B lines served as cross-reference to each other. 
TABLE 3: Genetic and physical mapping of G. arboreum-based EST-SSR markers. (—: physical mapping was inconclusive; X: unlinked marker).

\begin{tabular}{|c|c|c|c|c|}
\hline Marker & $\begin{array}{c}\text { Annealing } \\
\text { temperature }\left({ }^{\circ} \mathrm{C}\right)\end{array}$ & Euploid CS-B chromosome localization & $\begin{array}{l}\text { Aneuploid CS-B chromosome } \\
\text { localization }\end{array}$ & Linkage group \\
\hline MGAES-2 & 55 & - & - & LG 14 \\
\hline MGAES-3 & 55 & CS-B 01 & Te7Sh & LG 14 \\
\hline MGAES-5 & 55 & - & - & $\mathrm{X}$ \\
\hline MGAES-10 & 50 & CS-B 15Sh & - & $\mathrm{X}$ \\
\hline MGAES-11 & 50 & - & Te9Lo, H9 & LG 9 \\
\hline MGAES-21 & 55 & $\mathrm{XX}$ & Te20Lo, H20 & $\mathrm{X}$ \\
\hline MGAES-22 & 55 & CS-B 01 & - & $\mathrm{X}$ \\
\hline MGAES-25 & 55 & - & - & LG 5 \\
\hline MGAES-27 & 50 & - & - & $\mathrm{X}$ \\
\hline MGAES-28 & 55 & CS-B 10 & H3Sub, Te11Lo, H11, NTN12-11 & LG 7 \\
\hline MGAES-40 & 50 & CS-B26Lo & & $\mathrm{X}$ \\
\hline MGAES-41 & 55 & - & - & $\mathrm{X}$ \\
\hline MGAES-43 & 50 & - & - & $\mathrm{X}$ \\
\hline MGAES-44 & 55 & - & - & LG 5 \\
\hline MGAES-49 & 55 & - & - & LG 6 \\
\hline MGAES-51 & 55 & - & - & LG 6 \\
\hline MGAES-57 & 55 & NTN17-11 & H3Sub & $\mathrm{X}$ \\
\hline MGAES-58 & 55 & - & H3Sub & LG 10 \\
\hline MGAES-64 & 55 & CS-B 11Sh & Te11Lo, H11, NTN12-11 & LG 7 \\
\hline MGAES-72 & 55 & - & - & $\mathrm{X}$ \\
\hline MGAES-73 & 55 & - & - & $\mathrm{X}$ \\
\hline MGAES-78 & 55 & CS-B 11Sh & Te11Lo, H11 & LG 7 \\
\hline MGAES-80 & 55 & - & - & $\mathrm{X}$ \\
\hline MGAES-81 & 50 & - & - & $\mathrm{X}$ \\
\hline MGAES-82 & 55 & - & - & $\mathrm{X}$ \\
\hline MGAES-83 & 55 & CS-B04, CS-B 14Sh, NTN4-15, NTN10-19 & - & $\mathrm{X}$ \\
\hline MGAES-87 & 55 & CS-B 11Sh & Te11Lo, H10 & LG 4 \\
\hline MGAES-91 & 55 & - & - & $\mathrm{X}$ \\
\hline MGAES-95 & 55 & CS-B 02 & Te2Lo, H3SuB & $\mathrm{X}$ \\
\hline MGAES-104 & 50 & - & - & $\mathrm{X}$ \\
\hline MGAES-105 & 55 & - & Te15, Te20Lo, H3Sub & LG 5 \\
\hline MGAES-106 & 55 & CS-B26Lo & H12, NTN12-11 & LG 3 \\
\hline MGAES-107 & 55 & - & Te7Lo & $\mathrm{X}$ \\
\hline MGAES-111 & 50 & - & - & $\mathrm{X}$ \\
\hline MGAES-122 & 50 & CS-B 11Sh, NTN17-11 & - & LG 12 \\
\hline MGAES-126 & 50 & - & - & LG 8 \\
\hline MGAES-130 & 55 & NTN4-15 & H3Sub & LG 13 \\
\hline MGAES-135 & 55 & CS-B 18 & Te18Lo, H18 & LG 1 \\
\hline MGAES-141 & 55 & - & - & LG 2 \\
\hline MGAES-142 & 55 & - & $\mathrm{H} 10$ & $\mathrm{X}$ \\
\hline MGAES-143 & 55 & - & - & LG 11 \\
\hline MGAES-153 & 50 & CS-B 01 & - & $\mathrm{X}$ \\
\hline MGAES-157 & 55 & - & - & $\mathrm{X}$ \\
\hline MGAES-160 & 50 & - & - & $\mathrm{X}$ \\
\hline MGAES-161 & 50 & - & - & $\mathrm{X}$ \\
\hline MGAES-165 & 50 & - & - & $\mathrm{X}$ \\
\hline MGAES-194 & 55 & - & - & LG 2 \\
\hline MGAES-200 & 50 & - & - & $\mathrm{X}$ \\
\hline
\end{tabular}




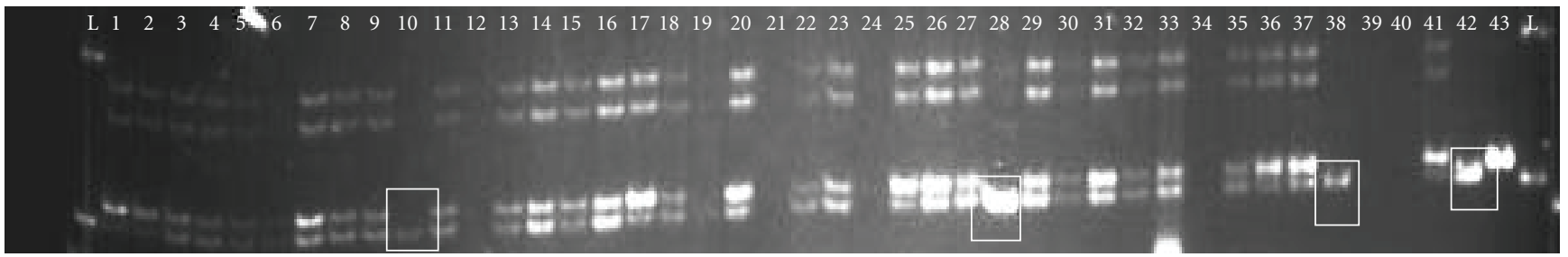

Figure 2: Chromosomal localization of EST-SSR marker MGAES-64 to Te11Lo (lane 10), H11 (lane 28), NTN12-11 (lane 38), and G. barbadense (lane 42) lines using aneuploid CS-B lines.

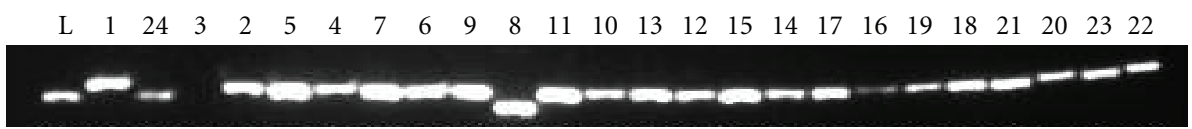

FIgURE 3: Chromosomal localization of EST-SSR marker MGAES-64 to CS-B 11Sh using euploid CS-B lines: sample 8: CS-B 11Sh, sample 24: G. barbadense (3-79).

For example, MGAES-64 marker was localized to H11 and Te11Lo aneuploid CS-B accessions where the accessions were deficient for chromosome 11 and its long arm, respectively; in both accessions the missing $G$. hirsutum fragment or locus has been observed confirming the localization of the marker to chromosome 11 and its long arm (Figure 2).

Using euploid chromosome substitution lines, the same MGAES-64 marker has been localized to CS-B11Sh accession, where a pair of chromosomes from G. barbadense was substituted for the long-arm deficient ditelosomic lines of $G$. hirsutum; polymorphic fragment corresponding to G. barbadense was only observed in CS-B11Sh explaining its localization to chromosome 11 long arm (Figure 3). Polymorphic markers, linkage group information, euploid, and aneuploid CS-B chromosome localization were shown in Table 3. However, we observed incongruency in localizing some markers to just a single chromosome using euploid and aneuploid CS-B analysis. This needs to be further investigated as it might be a result of duplicated loci or genome reorganization in some lines.

Our research demonstrated the use of gene-based markers for analyzing the genetic diversity among cultivated and wild cotton species. CAP markers proved more useful for detection of polymorphism in monomorphic fragments of closely related species. MGAES markers derived from G. arboreum ESTs were highly polymorphic and informative for developing genetic maps and other applications. Incorporation of the linkage groups and polymorphic markers into existing genetic maps help in developing integrated cotton genetic maps to assist cotton breeders.

\section{Abbreviations}

CAP: Cleaved amplified fragment polymorphism

EST: Expressed sequence tags

SSR: Simple sequence repeats

CS-B: Chromosome substitution lines of G. barbadense in G. hirsutum

RILs: Recombinant inbred lines

RFLP: Restriction fragment length polymorphism
AFLP: Amplified fragment length polymorphism

SNP: Single nucleotide polymorphism

CMD: Cotton Marker Database.

\section{Acknowledgments}

This paper was supported by USDA-CSREES Grant no. ALAX-011-706 to R. V. Kantety, ALAX-011-206 to G. C. Sharma, and NSF Plant Genome Research award no. 0703470 to R. V. Kantety. The authors would like to acknowledge the informatics and review support provided by $\mathrm{Mr}$. Venkateswara Rao Sripathi and other anonymous reviewers who assisted in improving the paper. This is journal article no. 629 of Alabama A\&M University Agricultural Experiment Station.

\section{References}

[1] A. J. Reinisch, J. M. Dong, C. L. Brubaker, D. M. Stelly, J. F. Wendel, and A. H. Paterson, "A detailed RFLP map of cotton, Gossypium hirsutum x Gossypium barbadense: chromosome organization and evolution in a disomic polyploid genome," Genetics, vol. 138, no. 3, pp. 829-847, 1994.

[2] J. F. Wendel, C. L. Brubaker, and A. E. Percival, "Genetic diversity in Gossypium hirsutum and the origin of upland cotton," American Journal of Botany, vol. 79, no. 11, pp. 12911310, 1992.

[3] Z. W. Shappley, J. N. Jenkins, C. E. Watson, A. L. Kahler, and W. R. Meredith, "Establishment of molecular markers and linkage groups in two F2 populations of upland cotton," Theoretical and Applied Genetics, vol. 92, no. 8, pp. 915-919, 1996.

[4] Z. W. Shappley, J. N. Jenkins, W. R. Meredith, and J. C. McCarty Jr., "An RFLP linkage map of Upland cotton, Gossypium hirsutum L," Theoretical and Applied Genetics, vol. 97, no. 5-6, pp. 756-761, 1998.

[5] M. K. Rana, V. P. Singh, and K. V. Bhat, "Assessment of genetic diversity in upland cotton (Gossypium hirsutum L.) breeding lines by using amplified fragment length polymorphism (AFLP) markers and morphological characteristics," Genetic Resources and Crop Evolution, vol. 52, no. 8, pp. 989-997, 2005. 
[6] A. M. Abdalla, O. U. K. Reddy, K. M. El-Zik, and A. E. Pepper, "Genetic diversity and relationships of diploid and tetraploid cottons revealed using AFLP," Theoretical and Applied Genetics, vol. 102, no. 2-3, pp. 222-229, 2001.

[7] J. M. Lacape, D. Dessauw, M. Rajab, J. L. Noyer, and B. Hau, "Microsatellite diversity in tetraploid Gossypium germplasm: assembling a highly informative genotyping set of cotton SSRs," Molecular Breeding, vol. 19, no. 1, pp. 45-58, 2007.

[8] S. Liu, R. G. Cantrell, J. C. McCarty, and J. M. Stewart, "Simple sequence repeat-based assessment of genetic diversity in cotton race stock accessions," Crop Science, vol. 40, no. 5, pp. 1459-1469, 2000.

[9] J. Rong, C. Abbey, J. E. Bowers et al., "A 3347-locus genetic recombination map of sequence-tagged sites reveals features of genome organization, transmission and evolution of cotton (Gossypium)," Genetics, vol. 166, no. 1, pp. 389-417, 2004.

[10] S. N. Qureshi, S. Saha, R. V. Kantety, and J. N. Jenkins, "Molecular biology and physiology: EST-SSR: a new class of genetic markers in cotton," Journal of Cotton Science, vol. 8, no. 2, pp. 112-123, 2004.

[11] S. Samuel Yang, F. Cheung, J. J. Lee et al., "Accumulation of genome-specific transcripts, transcription factors and phytohormonal regulators during early stages of fiber cell development in allotetraploid cotton," Plant Journal, vol. 47, no. 5, pp. 761-775, 2006.

[12] J. A. Udall, J. M. Swanson, K. Haller et al., "A global assembly of cotton ESTs," Genome Research, vol. 16, no. 3, pp. 441-450, 2006.

[13] P. W. Chee, J. Rong, D. Williams-Coplin, S. R. Schulze, and A. H. Paterson, "EST derived PCR-based markers for functional gene homologues in cotton," Genome, vol. 47, no. 3, pp. 449462, 2004.

[14] Z. Han, C. Wang, X. Song et al., "Characteristics, development and mapping of Gossypium hirsutum derived EST-SSRs in allotetraploid cotton," Theoretical and Applied Genetics, vol. 112, no. 3, pp. 430-439, 2006.

[15] Z. G. Han, W. Z. Guo, X. L. Song, and T. Z. Zhang, "Genetic mapping of EST-derived microsatellites from the diploid Gossypium arboreum in allotetraploid cotton," Molecular Genetics and Genomics, vol. 272, no. 3, pp. 308-327, 2004.

[16] Y. H. Park, M. S. Alabady, M. Ulloa et al., "Genetic mapping of new cotton fiber loci using EST-derived microsatellites in an interspecific recombinant inbred line cotton population," Molecular Genetics and Genomics, vol. 274, no. 4, pp. 428-441, 2005.

[17] W. Gao, Z. J. Chen, J. Z. Yu, R. J. Kohel, J. E. Womack, and D. M. Stelly, "Wide-cross whole-genome radiation hybrid mapping of the cotton (Gossypium barbadense L.) genome," Molecular Genetics and Genomics, vol. 275, no. 2, pp. 105-113, 2006.

[18] S. Saha, D. A. Raska, and D. M. Stelly, "Upland cotton (Gossypium hirsutum L.) x Hawaiian cotton (G. tomentosum Nutt. ex Seem.) F1 hybrid hypoaneuploid chromosome substitution series," Journal of Cotton Science, vol. 10, no. 4, pp. 263-272, 2006.

[19] D. Stelly, S. Saha, D. Raska, J. Jenkins, J. McCarty, and O. Gutierrez, "Registration of 17 upland (Gossypium hirsutum) cotton germplasm lines disomic for different G. barbadense chromosome or arm substitutions," Crop Science, vol. 45, no. 6, pp. 2663-2665, 2005.

[20] S. Saha, J. N. Jenkins, J. Wu et al., "Effects of chromosomespecific introgression in upland cotton on fiber and agronomic traits," Genetics, vol. 172, no. 3, pp. 1927-1938, 2006.
[21] N. Gutierrez, C. M. Avila, G. Duc et al., "CAPs markers to assist selection for low vicine and convicine contents in faba bean (Vicia faba L.)," Theoretical and Applied Genetics, vol. 114, no. 1, pp. 59-66, 2006.

[22] A. Blenda, J. Scheffler, B. Scheffler et al., "CMD: a Cotton Microsatellite Database resource for Gossypium genomics," BMC Genomics, vol. 7, no. 1, article 132, 2006.

[23] R. J. Kohel, J. Yu, Y. H. Park, and G. R. Lazo, "Molecular mapping and characterization of traits controlling fiber quality in cotton," Euphytica, vol. 121, no. 2, pp. 163-172, 2001.

[24] G. Figliuolo and P. Perrino, "Genetic diversity and intraspecific phylogeny of Triticum turgidum L. subsp. dicoccon (Schrank) Thell. revealed by RFLPs and SSRs," Genetic Resources and Crop Evolution, vol. 51, no. 5, pp. 519-527, 2004.

[25] R. V. Kantety, M. La Rota, D. E. Matthews, and M. E. Sorrells, "Data mining for simple sequence repeats in expressed sequence tags from barley, maize, rice, sorghum and wheat," Plant Molecular Biology, vol. 48, no. 5-6, pp. 501-510, 2002.

[26] S. Rozen and H. Skaletsky, "Primer3 on the WWW for general users and for biologist programmers," Methods in Molecular Biology, vol. 132, no. 3, pp. 365-386, 2000.

[27] S. Shete, H. Tiwari, and R. C. Elston, "On estimating the heterozygosity and polymorphism information content value," Theoretical Population Biology, vol. 57, no. 3, pp. 265$271,2000$.

[28] K. F. Manly, R. H. Cudmore, and J. M. Meer, "Map Manager QTX, cross-platform software for genetic mapping," Mammalian Genome, vol. 12, no. 12, pp. 930-932, 2001.

[29] I. Eujayl, M. Baum, W. Powell, W. Erskine, and E. Pehu, "A genetic linkage map of lentil (Lens sp.) based on RAPD and AFLP markers using recombinant inbred lines," Theoretical and Applied Genetics, vol. 97, no. 1-2, pp. 83-89, 1998.

[30] C. M. Ronning, S. S. Stegalkina, R. A. Ascenzi et al., "Comparative analyses of potato expressed sequence tag libraries," Plant Physiology, vol. 131, no. 2, pp. 419-429, 2003.

[31] S. Doganlar, J. Dodson, B. Gabor, T. Beck-Bunn, C. Crossman, and S. D. Tanksley, "Molecular mapping of the py-1 gene for resistance to corky root rot (Pyrenochaeta lycopersici) in tomato," Theoretical and Applied Genetics, vol. 97, no. 5-6, pp. 784-788, 1998.

[32] D. M. Stelly, S. Saha, D. A. Raska, J. N. Jenkins, J. C. McCarty, and O. A. Gutierrez, "Registration of 17 upland (Gossypium hirsutum) cotton germplasm lines disomic for different $G$. barbadense chromosome or arm substitutions," Crop Science, vol. 45, pp. 2663-2665, 2003.

[33] J. F. Wendel and R. C. Cronn, "Polyploidy and the evolutionary history of cotton," Advances in Agronomy, vol. 78, pp. 139-186, 2003.

[34] J. F. Wendel and V. A. Albert, "Phylogenetics of the cotton genus (Gossypium): character-state weighted parsimony analysis of chloroplast-DNA restriction site data and its systematic and biogeographic implications," Systematic Botany, vol. 17, pp. 115-143, 1992.

[35] T. Seelanan, A. Schnabel, and J. F. Wendel, "Congruence and consensus in the cotton tribe (Malvaceae)," Systematic Botany, vol. 22, no. 2, pp. 259-290, 1997.

[36] R. L. Small and J. F. Wendel, "Phylogeny, duplication, and intraspecific variation of Adh sequences in new world diploid cottons (Gossypium L., Malvaceae)," Molecular Phylogenetics and Evolution, vol. 16, no. 1, pp. 73-84, 2000.

[37] R. C. Cronn, R. L. Small, T. Haselkorn, and J. F. Wendel, "Rapid diversification of the cotton genus (Gossypium: Malvaceae) revealed by analysis of sixteen nuclear and chloroplast 
genes," American Journal of Botany, vol. 89, no. 4, pp. 707-725, 2002.

[38] J. F. Wendel, "New world tetraploid cottons contain old world cytoplasm," Proceedings of the National Academy of Sciences of the United States of America, vol. 86, pp. 4132-4136, 1989.

[39] J. F. Wendel, R. Rowley, and J. M. Stewart, "Genetic diversity in and phylogenetic relationships of the Brazilian endemic cotton, Gossypium mustelinum (Malvaceae)," Plant Systematics and Evolution, vol. 192, no. 1-2, pp. 49-59, 1994.

[40] O. T. Westengen, Z. Huamán, and M. Heun, "Genetic diversity and geographic pattern in early South American cotton domestication," Theoretical and Applied Genetics, vol. 110, no. 2, pp. 392-402, 2005.

[41] Y. H. Park, M. S. Alabady, M. Ulloa et al., "Genetic mapping of new cotton fiber loci using EST-derived microsatellites in an interspecific recombinant inbred line cotton population," Molecular Genetics and Genomics, vol. 274, no. 4, pp. 428-441, 2005.

[42] W. Guo, W. Wang, B. Zhou, and T. Zhang, "Cross-species transferability of G. arboreum-derived EST-SSRs in the diploid species of Gossypium," Theoretical and Applied Genetics, vol. 112, no. 8, pp. 1573-1581, 2006. 

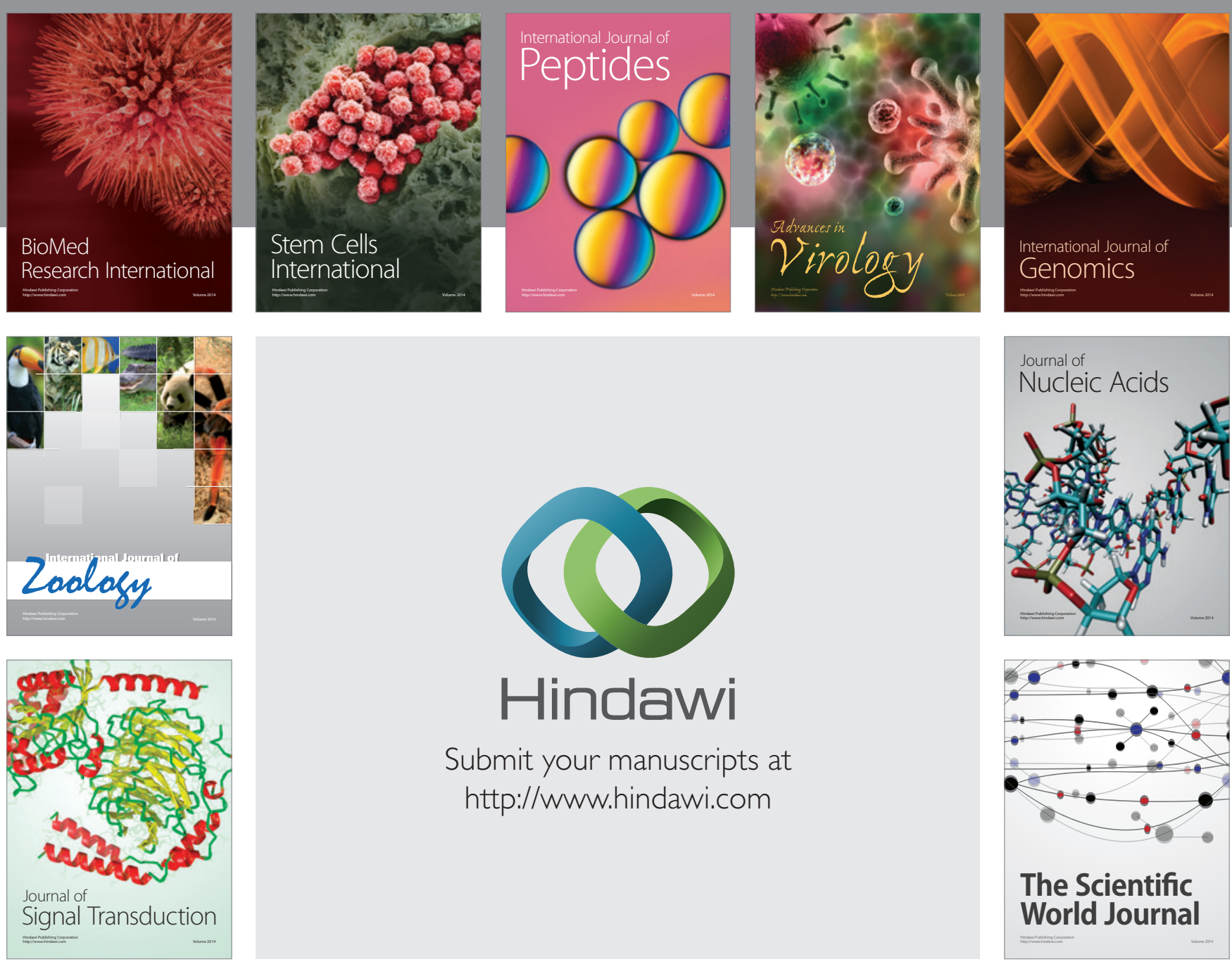

Submit your manuscripts at

http://www.hindawi.com
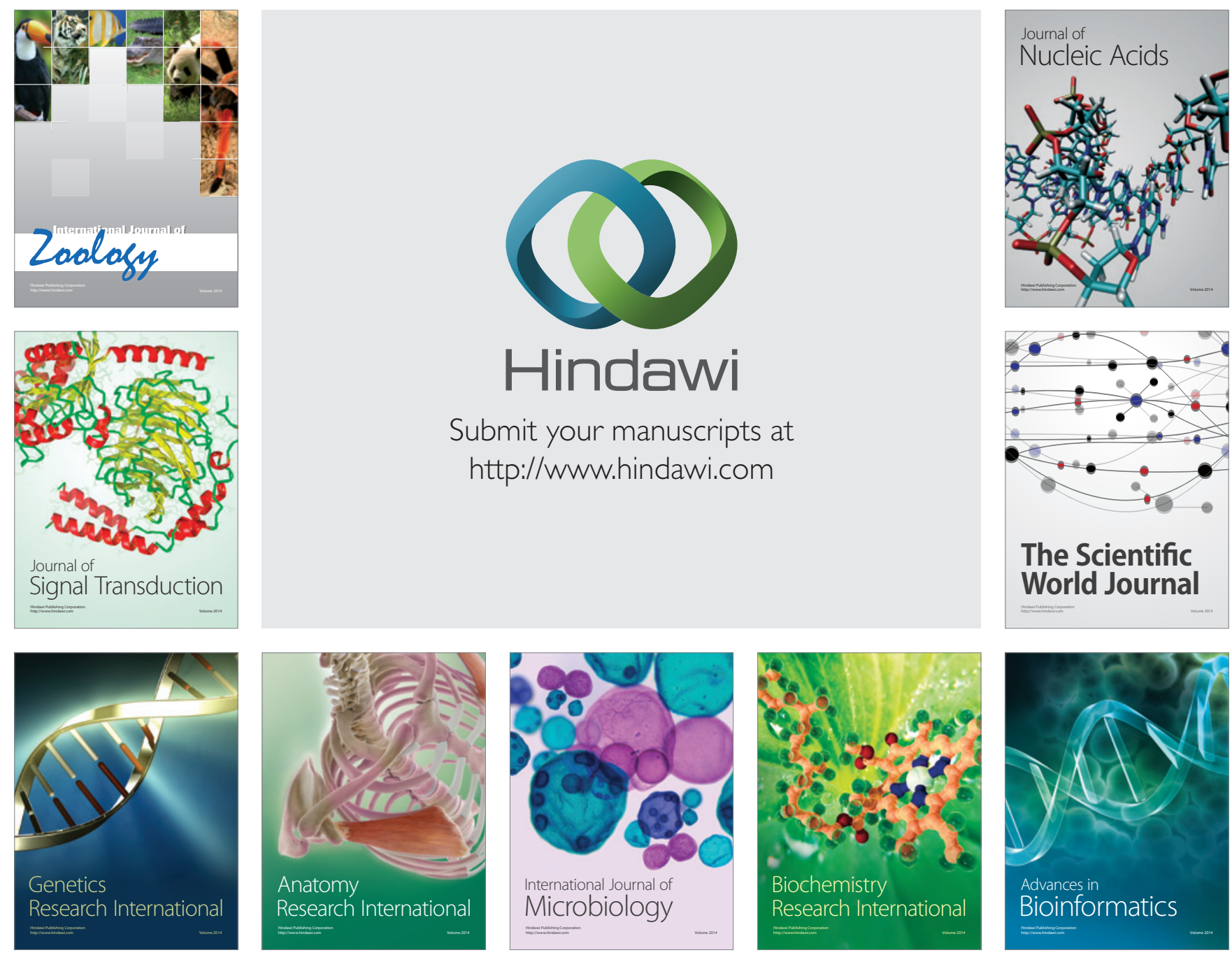

The Scientific World Journal
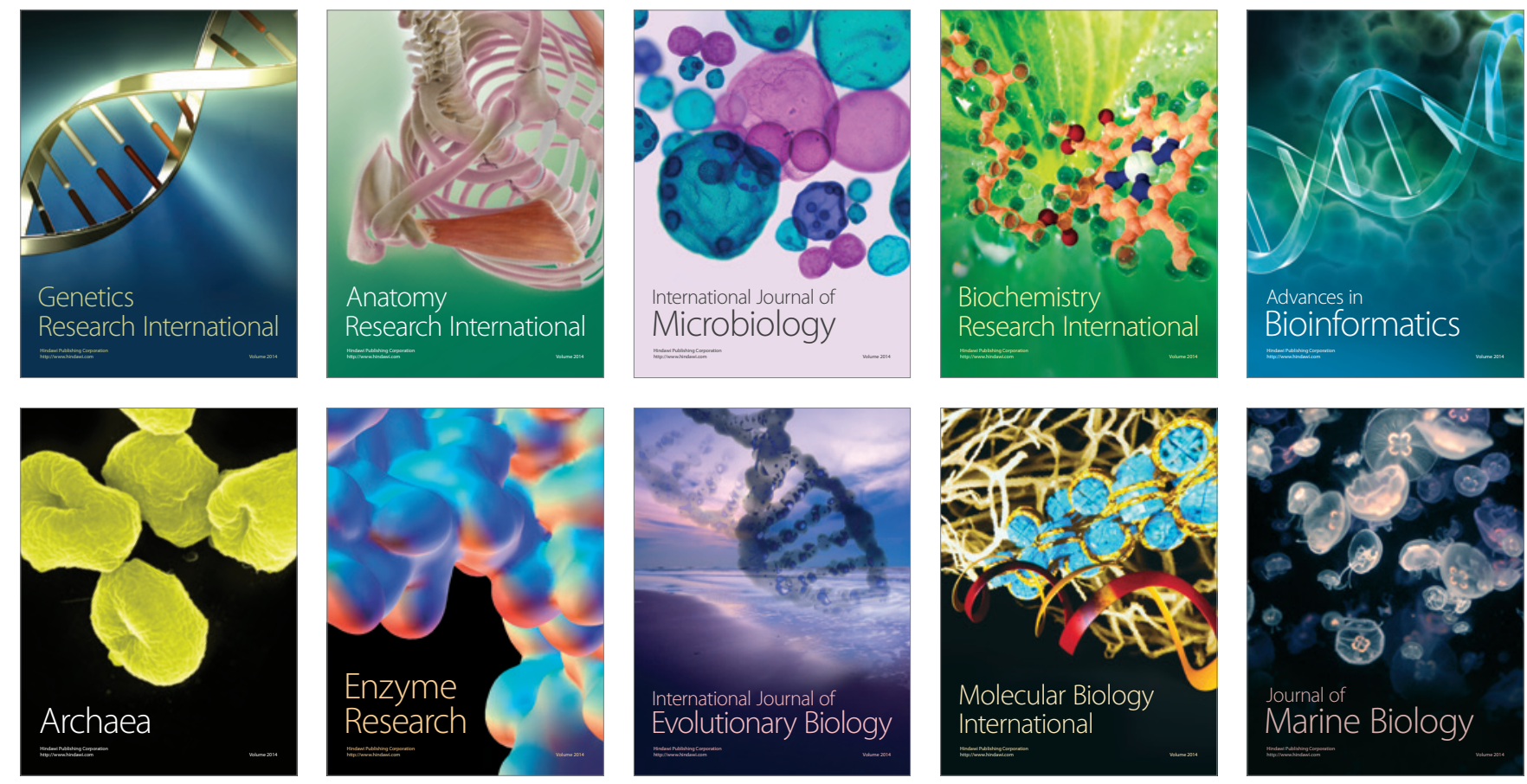